\title{
0 direito fundamental à saúde e o princípio da proteção integral da criança e do adolescente
}

The fundamental right to health and the principle of child and adolescent's full protection

\author{
Caroline Gazzola Subtil de Oliveira ${ }^{1}$ \\ Danielly Fernanda Beithum ${ }^{2}$ \\ Dianne Trindade Lima ${ }^{3}$
}

\section{Resumo}

0 presente artigo trata do direito fundamental à saúde como direito público subjetivo garantido pela Constituição Federal, e suas relações com o princípio da proteção integral, consagrado no Estatuto da Criança e do Adolescente. Pretendese, através desse estudo, expor os fundamentos do direito à saúde e sua disposição no texto constitucional, bem como sua abordagem pelo Estatuto da Criança e do Adolescente, visando à conscientização da necessidade e importância da efetiva realização do direito à saúde no seio social, precipuamente no que se refere à garantia de melhor qualidade de vida à população infanto-juvenil, tarefa essa que requer a colaboração e a atuação conjunta do Poder Público e de toda a sociedade.

Palavras Chave: Direito à saúde; Constituição Federal; Princípio da proteção integral; Estatuto da Criança e do Adolescente; Efetivação; Poder Judiciário.

\begin{abstract}
This article discuss about the fundamental right to health as a public and subjective right guaranteed by the Federal Constitution, as well its relations with the principle of child and adolescent's full protection, consecrated on the Statute of Child and Adolescent. It's intended, through the present research, an explosion the bases of the right to health e its disposition on the constitutional text, as well its approach by the Statute of Child and Adolescent, aiming the awareness on the necessity and importance of an effective realization of right to health in society, especially when it comes to the guarantee of better quality of life to children and adolescents, task which requires cooperation by the Public Power and the whole society.
\end{abstract}

Keywords: Right to health; Federal Constitution; Principle of full protection; Statute of the Child and Adolescent; Effectiveness; Judiciary Power.

\footnotetext{
${ }^{1}$ Acadêmica do 40 ano do curso de Direito da Universidade Estadual de Londrina (UEL).

${ }^{2}$ Acadêmica do 40 ano do curso de Direito da Universidade Estadual de Londrina (UEL).

${ }^{3}$ Acadêmica do 4ㅇano do curso de Direito da Universidade Estadual de Londrina (UEL).
} 


\section{Introdução}

A saúde é tema demasiadamente complexo, de modo que careceria de inumeráveis linhas para ser abordado com amplitude em todos os seus aspectos e dimensões. 0 presente artigo se propõe a analisar a saúde em sua feição jurídica, como direito público subjetivo e, de maneira mais específica, transportar o direito fundamental à saúde para o âmbito de estudos do Estatuto da Criança e do Adolescente.

O ordenamento jurídico-constitucional pátrio, considerando a saúde como pressuposto lógico para o exercício de tantos outros direitos considerados fundamentais, dentre os quais se insere o petrificado direito à vida, erigiu o direito à saúde ao patamar de direito fundamental, ofertando-Ihe inédita roupagem jurídica.

O Estatuto da Criança e do Adolescente (Lei n. 8.069/1990), ao aventar em seu bojo capítulo dedicado exclusivamente à regulamentação do direito à saúde, atribuiu-lhe específica e diferenciada feição, condizente com o princípio que norteia o referido diploma de lei em toda a sua extensão, qual seja, o princípio da proteção integral, segundo o qual crianças e adolescentes, devido à sua peculiar condição de pessoas em desenvolvimento, reivindicam maiores cuidados e especial proteção por parte do Estado e da sociedade.

Destarte, o direito à saúde, quando aplicado à realidade do Estatuto da Criança e do Adolescente, recebe tratamento diverso e é acrescido de novas características, fator essencial à sua plena concretização nas vidas dos pequenos cidadãos brasileiros.

Não se pode, contudo, negligenciar a brutal realidade que escancara, diariamente e às vistas de todos, as mazelas existentes no cenário brasileiro. Crianças e adolescentes são insistentemente privados do exercício pleno dos mais elementares direitos fundamentais, sobrevivendo, por diversas vezes, em condições subumanas, afastados sequer de um padrão mínimo de qualidade de vida. Nesse lamentável palco de miséria, o direito à saúde, entendido como corolário lógico do exercício dos demais direitos fundamentais, padece pela ausência de efetivação social.

Em meio a tal cenário, aparentemente irremediável, vislumbram-se ainda réstias de luz, consistentes, em considerável parcela, na incisiva defesa dos direitos infanto-juvenis por parte do Ministério Público. Destaque-se, ainda, a fundamental participação do Poder Judiciário no que concerne ao reconhecimento do direito à saúde, em sua peculiar faceta 
infanto-juvenil, no plano processual e em face da Administração Pública, contribuindo, dessa maneira, à efetivação do imprescindível direito à saúde na realidade das crianças e adolescentes.

Não obstante, conquanto de inegável relevância a função jurisdicional para a tutela do direito à saúde, sua veraz concretização no seio social e, especialmente, na realidade infanto-juvenil reclama a participação conjunta de toda a estrutura social, aí incluindo-se a máquina pública e as organizações civis, como a única maneira de se conferir ampla eficácia às disposições constitucionais referentes à saúde na sociedade brasileira.

\section{0 direito à saúde e a Constituição Federal de 1988}

Direitos fundamentais: conceito, características e aplicabilidade

Os direitos fundamentais constituem o cerne de todo ordenamento jurídico que se compromete, constitucional e infraconstitucionalmente, com a dignidade da pessoa humana e o Estado Democrático de Direito. Sem a plena realização desses direitos, não se torna possível, tampouco viável a concretização dos fundamentos e objetivos da República, enunciados de forma expressa na Carta Constitucional brasileira de 1988.

Ressalte-se ainda que o Direito, na condição de instrumento social normativo e permeado por valores, deve ser manejado de forma a proteger o ser humano em todas as suas dimensões, garantindo-Ihe as condições necessárias para uma vida digna em sociedade. Essa é a função a ser desempenhada pelo Estado Democrático de Direito, tendo em vista a realização dos direitos e garantias fundamentais no plano jurídico-social.

Tendo isso em mente, é de impreterível necessidade a exposição de conceito doutrinariamente elaborado acerca dos direitos fundamentais, como forma de abordagem ampla e, ao mesmo tempo, concisa sobre seus principais aspectos, que foram sendo desenvolvidos e construídos ao longo de sua trajetória na sociedade. Com fulcro na historicidade que Ihes é peculiar, os direitos fundamentais são assim definidos por Araújo e Nunes Júnior (2001, p. 79-80):

Categoria jurídica instituída com a finalidade de proteger a dignidade humana em todas as dimensões. Por isso, tal qual o ser humano, têm natureza polifacética, buscando resguardar o homem na sua liberdade (direitos individuais), nas suas 
necessidades (direitos sociais, econômicos e culturais) e na sua preservação (direitos relacionados à fraternidade e à solidariedade).

Os direitos fundamentais não surgiram repentinamente nem foram criados de uma só vez, mas são produto da história humana e dos embates travados no decorrer dos séculos, com o único objetivo de positivar valores inerentes à condição humana e que devem ser respeitados e resguardados pelo Estado. Esse é o caráter histórico dos direitos fundamentais, ou seja, a sua historicidade.

A universalidade é também qualidade imprescindível no tocante à caracterização dos direitos fundamentais. Mencionada característica revela que os direitos fundamentais são destinados a todos os seres humanos, em detrimento de divisões ou diferenças de qualquer natureza. Os direitos fundamentais não comungam de ideias segregacionistas ou discriminatórias, pois são estendidos a todas as pessoas em quaisquer tempo elugar.

Por derradeiro, porém não tencionando encerrar o caloroso debate a respeito das características dos direitos fundamentais, tem-se a irrenunciabilidade, em razão da qual os indivíduos não podem dispor desses direitos. Podem, entretanto, deixar de exercê-los, ainda que temporariamente, porém nunca renunciá-los.

A questão da aplicabilidade dos direitos fundamentais é bastante discutida no meio doutrinário por ser de primordial interesse da sociedade o efetivo alcance desses direitos a todos os cidadãos. A própria Constituição estatui, em seu artigo 5ํ, § 1ํㅡ, a aplicabilidade imediata dos direitos fundamentais. Isso significa dizer que tais normas, desde a sua entrada em vigor na Constituição Federal, são capazes de produzir, de forma imediata e plena, todos os efeitos sociais e jurídicos uma vez almejados pelo legislador constituinte.

Portanto, conclui-se que os direitos fundamentais, principais realizadores do postulado da dignidade da pessoa humana no Estado Democrático de Direito, foram elevados a um patamar de destaque no ordenamento jurídico brasileiro com o advento da Constituição de 1988. Tais direitos devem ser incorporados de forma a permearem todo 0 ordenamento jurídico, possibilitando a sua concretização não somente na esfera jurídica, mas primordialmente na social, destino e objetivo maior da própria existência dos direitos fundamentais.

Direitos fundamentais sociais: conceito, classificação e aplicabilidade 
Os direitos fundamentais, como já restou demonstrado, têm na historicidade sua essência. Significa dizer que, devido à formação e construção dos direitos fundamentais no transcorrer da história humana, é possível traçar uma classificação sistemática desses direitos, influenciada, em grande parte, pelo período histórico em que se desenvolveram.

Primeiramente, têm-se os direitos fundamentais individuais, também chamados direitos de primeira dimensão, enunciados na Declaração dos Direitos do Homem e do Cidadão (1789), fruto da Revolução Francesa, aos quais se atribui a qualidade de direitos civis e políticos por demandarem um comportamento de abstenção por parte do Estado. Os direitos à liberdade, à propriedade e à intimidade enquadram-se nessa categoria.

A evolução dos direitos fundamentais culminou, posteriormente, na consagração dos direitos de segunda geração, dos quais fazem parte os direitos econômicos, culturais e, em especial, os direitos sociais. Na esteira do brilhante magistério de José Afonso da Silva (2008, p. 286), referida categoria, diferentemente dos direitos individuais, requerem, para sua efetivação, intensa atuação do Estado para o fito de sanar as disparidades e desequilíbrios sociais:

São prestações positivas proporcionadas pelo Estado direta ou indiretamente, enunciadas em normas constitucionais, que possibilitam melhores condições de vida aos mais fracos, direitos que tendem a realizar a igualização de situações sociais desiguais.

São direitos que visam, portanto, a concretização do aspecto material da igualdade, mediante a satisfação das mais elementares necessidades humanas e o desfrute, por todos os cidadãos, de um padrão de vida condizente com os parâmetros constitucionalmente estabelecidos.

Os direitos sociais exigem, desse modo, a participação ativa do Estado em ações e políticas públicas que tenham por objetivo reduzir a desigualdade e proporcionar uma melhor qualidade de vida a todos os cidadãos, concretizando assim o princípio da dignidade da pessoa humana, que é o fundamento do ordenamento jurídico brasileiro e que norteia todas as normas de ordem constitucional.

O Capítulo II do Título II da Constituição Federal concentra-se em enunciar os direitos de cunho social, a saber: educação, saúde, trabalho, moradia, lazer, segurança, 
previdência social, proteção à maternidade e à infância e assistência social aos desamparados (art. 6ㅇ).

Neste palmilhar, de acordo com a classificação esposada por Silva (2008, p. 287), é possível bifurcar os direitos sociais em diversas categorias, quais sejam: (a) direitos sociais relativos ao trabalhador; (b) direitos sociais relativos à seguridade, compreendendo os direitos à saúde, à previdência e à assistência social; (c) direitos sociais relativos à educação e à cultura; (d) direitos sociais relativos à moradia; (e) direitos sociais relativos à família, criança, adolescente e idoso; (f) direitos sociais relativos ao meio ambiente.

Importa discutir aqui a aplicabilidade dos direitos sociais, tema de atual e inegável relevância jurídica, máxime em se considerando a deficitária proteção dispensada a esses direitos no plano social hodierno.

Parte da doutrina constitucionalista afirma serem os direitos sociais normas de eficácia limitada, de princípio programático e de aplicabilidade indireta, por necessitarem da integração da legislação infraconstitucional (Silva, 2008, p. 180).

Entretanto, tal posicionamento não condiz com 0 entendimento modernamente perfilhado pelas mais altas cortes de justiça pátrias no tocante à aplicabilidade das normas veiculadores de direitos sociais. É o que se extrai do voto exarado pelo Ministro Celso de M ello, do Supremo Tribunal Federal, no julgamento do Recurso Extraordinário 271.286-RS:

\footnotetext{
0 caráter programático (...) não pode converter-se em promessa constitucional inconsequente, sob pena de o Poder Público, fraudando justas expectativas nele depositadas pela coletividade, substituir, de maneira ilegítima, o cumprimento de seu impostergável dever por um gesto irresponsável de infidelidade governamental ao que determina a própria Lei Fundamental do Estado (STF, RE 271286 RS, Rel. Min. Celso de M ello, j. 02.08.2000, Dje 23.08.2000).
}

Logo, deve-se concluir que a efetivação dos direitos sociais, visando precipuamente à redução das desigualdades no plano social, não pode ficar à mercê da boa vontade do legislador em ofertar a tais direitos a necessária regulamentação legal, para que, enfim, sejam capazes de produzir os correlatos efeitos na seara jurídica. Ao revés, os direitos de cunho social são normas de aplicabilidade imediata, eficácia jurídica estendida a todos os direitos fundamentais pela própria Constituição Federal, possibilitando ao cidadão participação ativa na garantia e proteção desses direitos pelo Poder Público. 
O direito fundamental social à saúde e sua positivação na Constituição de 1988

A saúde, assim como todos os demais direitos de natureza social, sofreu os percalços de um moroso processo histórico até ser reconhecida e elevada à condição de direito fundamental do homem. A Declaração Universal dos Direitos Humanos (1940) traz, em seu artigo 25, precisa definição do direito à saúde, donde se extrai a conclusão de que a saúde não se restringe a significar a ausência de doença. Ao revés, abarca em sua definição jurídica outros direitos, que repercutem de igual maneira na qualidade de vida do ser humano. Assim estatui o mencionado dispositivo:

Toda pessoa tem direito a um padrão de vida capaz de assegurar a si e a sua família saúde e bem estar, inclusive alimentação, vestuário, habitação, cuidados médicos e os serviços sociais indispensáveis, e direito à segurança em caso de desemprego, doença, invalidez, viuvez, velhice ou outros casos de perda dos meios de subsistência fora de seu controle.

0 ordenamento jurídico brasileiro jamais houvera dispensado semelhante tratamento constitucional à saúde anteriormente à Carta Política de 1988, quando positivou no texto magno o direito público subjetivo à saúde, elevando-o ao patamar de direito social (art. 60, caput) e consagrando-o no Título referente à Ordem Social (art. 196 e ss.). Era de praxe, nas Constituições passadas, silenciar-se o legislador constituinte a respeito do tema, ou trazer, timidamente, poucas linhas acerca do assunto. Nas palavras do eminente constitucionalista José Afonso da Silva, "é espantoso como um bem extraordinariamente relevante à vida humana só agora é elevado à condição de direito fundamental do homem". (2008, p. 308).

0 art. 196 abraça a diretriz constitucional garantista, devendo servir de diretriz aos Poderes da República, cada qual no respectivo exercício de suas competências legais, a fim de se garantir o direito à saúde em todas as esferas estatais. A saúde, portanto, há de ser compreendida, nos termos propostos pelo artigo 196 da Carta Magna, como "direito de todos e dever do Estado, garantido mediante políticas sociais e econômicas que visem à redução do risco de doença e de outros agravos e ao acesso universal e igualitário às ações e serviços para sua promoção, proteção e recuperação". 
O dispositivo supra transcrito descortina dois princípios umbilicalmente vinculados à saúde pública, isto é, os princípios da universalidade e da igualdade. 0 primeiro consagra a saúde como direito fundamental, destinado ao ser humano de forma universal, impedindo assim restrições de qualquer natureza ao seu pleno e irrestrito acesso. 0 segundo reforça a ideia de que pessoas na mesma situação clínica devem receber igual atendimento (Araújo, Nunes Júnior, 2001, p. 382).

A Constituição Federal explicita, ademais, a possibilidade de reivindicação do pleno acesso à saúde por intermédio de mecanismos judiciais, perante o Poder Judiciário, seja por meio da ação de inconstitucionalidade por omissão (artigos 102, l, a, e 103, § 2ㅇ), seja através da impetração de mandado de injunção (artigo 5ำ, inciso LXXI).

Faz-se mister discutir a aplicabilidade do direito à saúde, que, na condição de "direito fundamental do homem, tem-se que as normas constitucionais referentes à saúde são normas de aplicabilidade imediata e de eficácia plena" (Morais, Schwartz e Pilau Sobrinho, 2003, p. 635). Desse entendimento comungam as mais recentes decisões das instâncias judiciárias, representando importante marco na evolução da saúde como direito fundamental social.

Destarte, é de incontestável legitimidade 0 entendimento que privilegia 0 direito à saúde segundo sua ótica constitucional, conduzindo-o ao patamar de direito fundamental, cuja efetiva concretização no plano social carece da atuação de toda a sociedade. A preocupação advinda do comportamento negligente por parte do Poder Público perante as questões concernentes à saúde reflete-se no magistério de Ingo Wolfgang Sarlet (2004, p. 346):

A denegação dos serviços essenciais de saúde acaba - como sói acontecer - por se equiparar a uma pena de morte, sem crime, sem qualquer processo e, na maioria das vezes, sem possibilidade de defesa, isto sem falar na virtual ausência de responsabilização dos algozes, abrigados pelo anonimato dos poderes públicos.

\section{0 direito à saúde e 0 Estatuto da Criança e do Adolescente}

A doutrina da proteção integral e suas dimensões 
A Lei 8.069, de 13 de julho de 1990, trouxe nova identidade jurídica à proteção legal das crianças e adolescentes, pautando-se de acordo com os parâmetros preestabelecidos na Constituição Federal de 1988 e em outras legislações de ordem internacional.

0 Estatuto da Criança e do Adolescente consagrou, logo em seu art. 1ํ, o princípio da proteção integral, que irá permear todos os dispositivos subsequentes, bem como nortear a interpretação do referido diploma legal e da ulterior legislação esparsa. A razão acompanha Paulo Vercelone (Cury, 2006, p. 32) quando expõe acerca da inovação capitaneada pelo legislador ordinário e explicitada no Estatuto:

Trata-se da técnica legislativa quando se faz uma revolução, quando se reconhece que uma parte substancial da população tem sido até o momento excluída da sociedade e coloca-se agora em primeiro plano na ordem de prioridade dos fins a que o Estado se propõe.

A doutrina da proteção integral há de ser compreendida como o complexo de direitos e garantias endereçado com exclusividade à criança e ao adolescente, que, na condição de pessoas em desenvolvimento, apresentam-se como titulares de direitos específicos e peculiares, sem prejuízo de todos os demais direitos fundamentais garantidos à pessoa humana em sede constitucional.

Não bastasse isso, o princípio da proteção integral outorga expressamente, a todos aqueles que estiverem, de alguma forma, adstritos à responsabilidade legal para com as crianças e os adolescentes, o dever de assegurar, com absoluta primazia, a efetivação dos direitos à vida, à saúde, à alimentação, à educação, ao esporte, à cultura, à dignidade, ao respeito, entre outros.

Significa dizer que, devido à sua condição de pessoas em desenvolvimento, as crianças e os adolescentes figuram em posição de absoluta ou relativa dependência, necessitando, portanto, de cuidados e proteção peculiares. Assim preceitua Dalmo de Abreu Dallari (2006, p. 37): “[...] são igualmente responsáveis pela criança a família, a sociedade e o Estado, não cabendo a qualquer dessas entidades assumir com exclusividade as tarefas, nem ficando alguma delas isenta de responsabilidade."

A proteção integral também compreende a absoluta prioridade que deve ser estendida às crianças e aos adolescentes, principalmente no tocante à formulação e 
execução de políticas sociais públicas e na destinação de recursos públicos nas áreas relacionadas com a proteção à infância e à juventude (artigo 4ํ, parágrafo único).

Essa incumbência, atribuída obrigatória e primordialmente aos governantes, expressa a necessidade de cuidado e proteção a ser dispensada, de maneira especial, àqueles que estão em processo de desenvolvimento, o que pressupõe sua maior fragilidade, dependência e exposição a riscos.

Por derradeiro, deve-se reconhecer, com supedâneo no princípio da proteção integral, que a criança e o adolescente representam o "futuro da sociedade", para fazer uso de jargão amiúde propalado, porém inegavelmente genuíno. A nação que hasteia esse preceito como bandeira precursora de seu desenvolvimento, investindo na formação educacional e, de um modo geral, cultural dos cidadãos mirins, certamente colherá, em futuro próximo ou longínquo, os frutos dessa política protecionista dos direitos das crianças e adolescentes.

0 direito fundamental à saúde e suas relações com o princípio da proteção integral

O Brasil passou por uma reforma sanitária com o advento da Constituição Federal de 1988, em cujo bojo inaugurou o Sistema Único de Saúde (SUS) e instituiu princípios básicos a serem seguidos pelos órgãos estatais em todo o âmbito da federação no que diz respeito à saúde.

O Estatuto da Criança e do Adolescente - como é de praxe fazer o legislador em grande parte dos diplomas jurídicos posteriores à Carta Magna de 1988 - reforçou alguns princípios constitucionais, moldando-os segundo as específicas necessidades das crianças e dos adolescentes, máxime nas disposições referentes à saúde.

A efetivação dos princípios sanitários requer, além dos cuidados e da proteção a serem dispensados durante 0 tratamento da doença, ações preventivas que objetivem a redução dos casos de contaminação e mortalidade, além da criação de programas e serviços sociais que promovam e possibilitem a melhoria da qualidade de vida da população.

Assim dispõe 0 art. 200 da Constituição Federal, quando trata das atribuições conferidas ao SUS, dentre elas: executar as ações de vigilância sanitária e epidemiológica, bem como as de saúde do trabalhador; participar da formulação da política e da execução das ações de saneamento básico; fiscalizar e inspecionar alimentos, compreendido o 
controle de seu teor nutricional, bem como bebidas e águas para consumo humano; colaborar na proteção do meio ambiente, nele compreendido o do trabalho.

A Lei n. 8.069/1990 abrigou de modo implícito todas essas diretrizes em seu artigo 11, estabelecendo, todavia, uma proteção diferenciada e especial atribuída à criança e ao adolescente no tocante aos serviços e ações na área da saúde, concretizando, assim, o princípio da proteção integral. Tal proteção, como outrora asseverado, se estende por inúmeras confluências, afigurando-se como uma rede de proteção específica conferida aos cidadãos mirins, com direitos e garantias amplos e especiais, inerentes à sua condição de pessoas em desenvolvimento, responsabilizando a sociedade em conjunto pela garantia e efetivação de tais direitos e reservando-Ihes absoluta prioridade.

0 direito à saúde incorporou tal roupagem jurídica uma vez inserido no Estatuto da Criança e do Adolescente, refletindo as dimensões e características ínsitas à doutrina da proteção integral. Aludida diretriz faz-se notável logo no início do capítulo referente ao direito à vida e à saúde, que confere à gestante e ao nascituro direitos essenciais, tais como 0 atendimento pré e perinatal, o apoio alimentar durante as fases de gestação e de amamentação, as condições adequadas ao aleitamento materno, 0 atendimento básico e necessário a ser dado à gestante e ao neonato durante o período pós-parto nos hospitais, entre outros.

Os artigos subsequentes trazem outras disposições relacionadas com o direito à saúde e a doutrina da proteção integral, como, a título de exemplificação, o art. 12, que ordena aos estabelecimentos de atendimento à saúde a criação de condições para a permanência em tempo integral de um dos pais ou responsável, nos casos de internação da criança e do adolescente.

Nos parâmetros do artigo 14, incumbe ao SUS a promoção de programas de assistência médica e odontológica para a prevenção de enfermidades que ordinariamente afetam a população infantil, e campanhas de educação sanitária para pais, educadores e alunos, além da obrigatoriedade de vacinação das crianças nos casos recomendados pelas autoridades sanitárias (parágrafo único).

Vê-se, portanto, que o princípio da proteção integral permeia todo o Estatuto da Criança e do Adolescente, conferindo a cada direito e garantia um tratamento diferenciado. 0 direito à saúde não foi excluído do alcance desse princípio, sendo minuciosamente 
abordado no Estatuto, com todas as nuances necessárias à efetiva proteção da criança e do adolescente na área sanitária.

Compete ao Poder Público, precipuamente, e à sociedade em conjunto, agora que já positivadas tais diretrizes no ordenamento jurídico brasileiro, oferecer as necessárias condições de eficaz implemento das políticas - públicas ou provenientes da iniciativa privada - protetivas dos direitos da criança e do adolescente no âmbito da saúde, que ainda carece de incontáveis recursos e ações efetivas por parte daqueles a quem a lei atribuiu inúmeras responsabilidades no tocante ao cuidado aos cidadãos menores.

\section{A atuação do judiciário e do Ministério Público na garantia dos direitos da criança e do adolescente na área da saúde}

O século XXI, em termos de estruturação do poder estatal, tem sido apontado por estudiosos como o século do Poder Judiciário, compreendido, na perspectiva contemporânea, como genuíno poder político, protagonista na resolução dos conflitos e questões sociais de maior relevância. Faz-se menção ao fenômeno do ativismo judicial para descrever a atuação engajada da magistratura na salvaguarda e defesa da Constituição Federal, extraindo dos preceitos constitucionais, por intermédio de interpretações extensivas, todo o seu potencial hermenêutico, a fim de concretizar os princípios, direitos e garantias fundamentais ali inscritos.

A hodierna ascensão institucional do Poder Judiciário, para lançar de mão de expressão cunhada pelo jurista Luís Roberto Barroso (2010, p. 4), é atribuída a diversos fatores, dentre os quais o descrédito porque passam as demais instâncias de poder, representadas pelos Poderes Legislativo e Executivo, perante a sociedade, sem falar, outrossim, na recente constitucionalização de temas de inegável interesse social, tais como as uniões homoafetivas e o direito da mulher de interromper a gestação. Referidas questões, conquanto ostentem indubitável conteúdo social, envolvem matéria essencialmente constitucional, passíveis de apreciação, portanto, pelas instâncias judiciárias.

No que concerne ao curial aspecto dos direitos infanto-juvenis, nota-se, da mesma maneira, ativa participação do Poder Judiciário na garantia dos interesses dos menores, em observância aos princípios da dignidade da pessoa humana e da proteção integral. 
A atuação do Ministério Público cinge-se à defesa dos direitos difusos e coletivos, cuja via judicial mais adequada para tanto faz-se por intermédio da propositura de ação civil pública, competência constitucionalmente delegada ao parquet (artigo 129, inciso III, CF). A propósito, convém salientar que o Estatuto da Criança e do Adolescente, alargando as atribuições constitucionais do Ministério Público, incumbiu-lhe o dever de zelar pela proteção dos interesses meramente individuais, desde que relativos à infância e à adolescência (artigo 201, inciso V, da Lei n. 8.069/1990).

Diversos são os temas debatidos em torno do direito infanto-juvenil à saúde, perpassando por questões referentes à legitimidade do Ministério Público para figurar no polo ativo de demanda judicial cujo objeto diga respeito a interesse individual de criança ou adolescente, até discussões envolvendo conflito de valores, ou mesmo interesses, representado, de um vértice, pela Administração Pública, e, de outro, pelo direito fundamental à saúde do qual se mune o jovem cidadão.

Importa para o presente artigo a análise empírica de casos concretos e decisões judiciais que apresentem, no cerne de seus respectivos embates, polêmicas e controvérsias relacionadas ao direito à saúde na esfera protetiva do Estatuto da Criança e do Adolescente.

Bastante controvertida é a discussão acerca da legitimidade do Ministério Público para promover ação civil pública em favor de interesse meramente individual que estivesse diretamente vinculado a questões sanitárias na esfera infanto-juvenil. Destaquem-se, nessa hipótese, os casos concernentes à prestação de serviços e tratamentos hospitalares e ao fornecimento de medicamentos, situações concretas amiúde recorrentes no âmbito do Poder Judiciário

A jurisprudência pátria é assente no que se refere à legitimidade ad causam do órgão ministerial para figurar no pólo ativo de demanda judicial, pugnando em favor de interesse de menor, ainda que meramente individual, haja vista, sobretudo, a existência de expressa disposição legal referente ao tema, com diretriz cristalizada no artigo 201, inciso V, da Lei n. 8.069/1990, supracitado.

Não obstante, há ainda inúmeros julgados que versam sobre o assunto, mormente em se considerando que os argumentos suscitados no sentido de suprimir a legitimidade do parquet provêm, em sua grande maioria, da parte adversária. As decisões judiciais, 
entretanto, pacificam-se na direção alhures explicitada, condizente, portanto, com disposição de lei arraigada no Estatuto da Criança e do Adolescente.

Tal se depreende de sucessivos julgados outrora em trâmite perante o Superior Tribunal de Justiça, dentre os quais o agravo regimental interposto, em sede de recurso especial, pelo Município do Rio de Janeiro, de relatoria do Ministro Herman Benjamin, contra decisão que deu provimento a recurso especial interposto pelo Ministério Público Estadual.

O M unicípio do Rio de Janeiro impugnara a aludida decisão sob a alegação de que o M inistério Público era parte ilegítima para figurar como autor de ação civil pública em defesa de interesse individual de menor.

Colacionando diversos excertos de julgados da mesma colenda corte de justiça, o ilustre Ministro, seguido pelos demais magistrados integrantes da Segunda Turma do Superior Tribunal de Justiça, proferiu voto nos seguintes termos:

(...) é pacífico neste Superior Tribunal de Justiça o entendimento segundo o qual o Ministério Público tem legitimidade para propor Ação Civil Pública com o intuito de resguardar direito individual indisponível, como ocorre na presente lide, que se refere à defesa do direito à saúde de menor carente (STJ, AgRg no Recurso Especial no 946.973, Rel. Min. Herman Benjamin, j. 05.06.2008).

Consoante alhures declinado, o Estatuto da Criança e do Adolescente confere ao M inistério Público competência para atuar em prol dos direitos e interesses da criança e do adolescente, fazendo-o por intermédio da propositura de ação civil pública, ainda quando a ação tenha por objeto interesse de pessoa individualmente considerada.

Tal se explica com supedâneo na doutrina da proteção integral, peculiar à matéria jurídica infanto-juvenil. Os postulados de referida doutrina decorrem da necessidade de concessão de tratamento legal específico, diferenciado e amplo à criança e ao adolescente, donde se extrai a previsão da competência ministerial para promover ação civil pública em benefício de menor, visando, desse modo, à salvaguarda ampla e irrestrita dos direitos e interesses do infante e do jovem.

A saúde deve ser enfocada sob prisma essencialmente constitucional, que a elevada à condição de direito fundamental, bem jurídico a ser tutelado pelo Estado em todas as instâncias federativas e pressuposto essencial ao exercício dos demais direitos 
fundamentais, dentre os quais o direito à vida. Essa é a diretriz pela qual se pauta o ilustre M inistro Celso de M ello, do Supremo Tribunal Federal:

Entre proteger a inviolabilidade do direito à vida, que se qualifica como direito subjetivo inalienável assegurado pela própria Constituição da República (art. 50, caput), ou fazer prevalecer, contra essa prerrogativa fundamental, um interesse financeiro e secundário do Estado, entendo - uma vez configurado esse dilema que razões de ordem ético-jurídica impõem ao julgador uma só e possível opção: 0 respeito indeclinável à vida. (STF, AgRg n. 1246, rel. Min. Sepúlveda Pertence, j. 10.04.1997)

O excerto supratranscrito evidencia enfrentamento de natureza constitucional entre valores ou princípios sagrados no texto magno, suscitado em caso concreto, e que demanda, destarte, decisão judicial com observância inarredável ao princípio, também de ordem constitucional, da proporcionalidade. Em apertada síntese, a aplicação do mencionado princípio ao caso sub judice revela-se na ponderação dos interesses em conflito, devendo o julgador, ao sopesá-los sobre a balança da justiça, resolver o embate em favor daquele cuja carga axiológica imperar com maior preponderância na situação concreta.

A sobreposição do direito à saúde e, via de consequência, do direito à vida, face aos interesses de ordem financeira e orçamentária do Estado deve estabelecer-se como regra nas decisões do Poder Judiciário, com estrita observância, naturalmente, às circunstâncias do caso concreto.

Ocorre que, lastimavelmente, em grande parte das situações, lança-se mão de infrutíferos argumentos, tais como a possibilidade de desequilíbrio no orçamento da Administração Pública ou a desarmonia entre os Poderes da República, com a invasão do âmbito de competências do Poder Executivo pelo Poder Judiciário, como forma de se escusar do adimplemento de dever imposto em sede constitucional ao Estado (artigo 196, CF), que arrogou a si a qualificação de Estado Democrático de Direito e, portanto, Estado Social de Direito, principal provedor e assegurador de um patamar mínimo de condições de vida aos seus cidadãos.

Inobstante, não se deve extrapolar as fronteiras juridicamente permitidas debaixo do manto de referida alegação, sob pena de transmudar-se o nobre propósito em discurso demagogo. Cada caso necessita de apreciação minuciosa do julgador que o preside, devendo 
ser consideradas as alegações arguidas por ambas as partes e providas na proporção de seu acerto e veracidade.

Todavia, não são dignas de chancela popular aquelas decisões que ataquem frontalmente o direito à saúde do qual se mune o cidadão em juízo, eximindo o Estado de zelar por dever que ele próprio a si mesmo imputou na qualidade de Estado de Direito Social e Democrático. Felizmente, reiterados julgados prodigalizam o entendimento que melhor se coaduna com a opção eleita pelo legislador constituinte:

0 Estado, ao negar a proteção perseguida nas circunstâncias dos autos, omitindose em garantir o direito fundamental à saúde, humilha a cidadania, descumpre 0 seu dever constitucional e ostenta prática violenta de atentado à dignidade humana e à vida. É totalitário e insensível (ST), Recurso Especial no 904.443/RS, rel. M in. José Delgado, j. 13.02.2007).

Ainda:

O Estado, ao se negar a essa prestação fundamental à criança pobre, nas circunstâncias dos autos, humilha a cidadania, descumpre o seu dever e ostenta praticar violento atentado à dignidade humana e à vida (STF, PetM C. 1.246-SC, Rel. Min. Celso de Mello, j. 31.1.1997).

Por derradeiro, cumpre transcrever relevante excerto de julgado do Superior Tribunal de Justiça acerca do princípio da proteção integral aplicado em específico à seara do direito à saúde:

Sem sombra de dúvida, nenhuma interpretação jurídica ou lei hierarquicamente inferior pode trazer restrições, de modo a negar efetividade jurídica a direitos afetos às crianças e adolescentes, garantidos constitucionalmente. A doutrina da proteção integral implica necessariamente o reconhecimento de que as crianças e adolescentes, por serem pessoas em desenvolvimento, necessitam de proteção especial, diferenciada e integral. (...) Se o espírito de proteção integral à criança e ao adolescente foi inserido na Constituição Federal e consagrado e sintetizado no Estatuto da Criança e do Adolescente, é porque nossas leis estão refletindo e representando quais as prerrogativas que devem ser prioritariamente observadas, entre as quais, discutida no caso em tela, inclui-se a assistência médica aos menores em todos os âmbitos do Poder Público (ST), Recurso Especial № 577.836, Rel. Min. Luiz Fux, j. 21.10.2004).

Logo, com fulcro nas decisões alhures colacionadas, vislumbra-se atuação de inegável relevância social por parte do Ministério Público e do Poder Judiciário na garantia e 
salvaguarda dos cidadãos menores e hipossuficientes. A ativa participação dos órgãos ministeriais e judiciários não deve, contudo, ser confundida com injusta imparcialidade. Ao revés, necessita ser compreendida sob a ótica dos valores constitucionais e legais nos quais deve ser pautar toda e qualquer decisão judicial, com especial enfoque àqueles concernentes à proteção integral dos direitos e interesses da criança e do adolescente.

\section{Conclusão}

O direito à saúde, bem jurídico elevado a posição de destaque no texto constitucional e amiúde intitulado de direito fundamental, albergou nova roupagem legal com 0 advento da Lei n. 8.069/1990, o Estatuto da Criança e do Adolescente.

$\mathrm{Na}$ seara desse diploma de lei, o direito à saúde deve ser, inarredavelmente, vislumbrado sob a ótica do princípio da proteção integral, que norteia a interpretação e aplicação da Lei n. 8.069/1990 em todos os aspectos, de maneira a conferir-Ihe nova perspectiva, condizente com o estado de imaturo desenvolvimento ostentado pelos cidadãos menores, que demandam, portanto, resguardo abrangente e diferenciado.

Nesse cenário, observa-se engajada participação do Ministério Público, titular legítimo da defesa dos interesses individuais da criança e do adolescente por intermédio da ação civil pública, e do Poder Judiciário na salvaguarda dos direitos infanto-juvenis, com supedâneo na doutrina da proteção integral e na magnitude axiológica do direito à saúde, dever inescusável do Estado de Direito Social e Democrático que, com estrita observância ao princípio da proporcionalidade, sobrepuja-se aos demais interesses em conflito sub judice.

Contudo, a despeito da ativa participação envidada pelo parquet e pelas instâncias judiciárias no tocante à garantia dos direitos e interesses infanto-juvenis, a atuação do Estado e da sociedade não deve se restringir aos inanimados autos processuais. A real efetivação, no plano social, dos direitos das crianças e dos adolescentes, com especial enfoque ao direito à saúde, carece da atuação engajada por parte de entidades sociais e estatais, a fim de que seja soprado fôlego de vida aos textos legais, maiores guardiães dos direitos das crianças e adolescentes.

\section{Referências}

ARAÚJO, Luiz Alberto David; NUNESJÚNIOR, Vidal Serrano. Curso de Direito Constitucional. 4ạ edição. São Paulo: Saraiva, 2001. 
BARROSO, Luís Roberto. Constituição, Democracia e Supremacia Judicial: Direito e Política no Brasil contemporâneo. In: Revista Jurídica da Presidência. Brasília, vol. 12, fev/mai 2010.

BRASIL. Constituição (1988). Constituição da República Federativa do Brasil. Disponível em: বhttp://www.planalto.gov.br/ccivil_03/Constituicao/Constituiçao.htm>. Acesso em: 15 jun. 2011.

. Lei $n^{\circ} 8.069$, de 13 de julho de 1990. Dispõe sobre o Estatuto da Criança e do Adolescente e dá outras providências. Disponível em: বtttp://www.planalto.gov.br/ccivil_03/Leis/L8072.htm>. Acesso em: 15 jun. 2011.

CURY, M unir (Coord.). Estatuto da criança e do adolescente comentado. 8a edição. São Paulo: Malheiros, 2006.

M ORAIS, Jose Luis Bolzan De; SCHWATRZ, Germano André D.; PILAU SOBRINHO, Liton Lanes. Análise jurídico-constitucional do direito à saúde. In: Direitos sociais e políticas públicas: desafios contemporâneos. Rogério Gesta Leal; Luiz Ernani Bonesso de Araújo (organizadores). Santa Cruz do Sul: EDUNISC, 2003.

SARLET, Ingo Wolfgang. A eficácia dos direitos fundamentais. 4a edição. Porto Alegre: Livraria do Advogado, 2004.

SILVA, José Afonso da. Curso de Direito Constitucional Positivo. 30a edição. São Paulo: Malheiros, 2008. 